\title{
Sesamoid bones of the hand: A multicenter study
}

\author{
Osman Civan, $\mathrm{MD}^{1}{ }^{1}$, Rahime Şekerci, $\mathrm{MD}^{2}{ }^{\mathbb{D}}$, Nurcan Ercıktı, $\mathrm{MD}^{3} \mathbb{D}$, Şule Özer, $\mathrm{MD}^{4} \mathbb{( D}$,

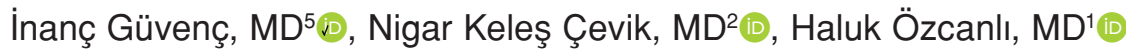

1Department of Orthopedics and Traumatology, Akdeniz University Faculty of Medicine, Antalya, Turkey

${ }^{2}$ Department of Anatomy, Akdeniz University Faculty of Medicine, Antalya, Turkey

${ }^{3}$ Department of Anatomy, University of Health Sciences, Gülhane Faculty of Medicine, Ankara, Turkey

${ }^{4}$ Department of Radiology, Çanakkale Onsekiz Mart University Faculty of Medicine, Çanakkale, Turkey

${ }^{5}$ Department of Radiology, University of Health Sciences, Gülhane Faculty of Medicine, Ankara, Turkey

Sesamoid bones (SBs) are the skeletal variations of the hand and foot that were first described by Galen. ${ }^{[1]}$ They are mostly located on the hands and feet region; they can be found under the tendon passing over the joint. However, they can also be found in other locations such as the largest sesamoid-patella, pisiform in the wrist, and fabella in the knee.

Two main hypotheses have been described for the SB development: functional and phylogenetic. ${ }^{[2-4]}$ In 2018, Yammine ${ }^{[5]}$ added a new hyperextension hypothesis to these two hypotheses and explained the frequency of sesamoids in human digits. There is still no consensus concerning the function of the sesamoids. They are part of a gliding mechanism. Sesamoids function by reducing the friction and modifying the pressure. They also change the direction of the muscle's force and protect the tendon. ${ }^{[6]}$

Sesamoid bone is a frequent finding in routine radiographs of the hand. Unfortunately, pathological conditions of the SB are usually overlooked. Physicians focus on the larger osseous structures

Received: August 23, 2019

Accepted: September 17, 2019

Published online: March 02, 2020

Correspondence: Osman Civan, MD. Yeni Mahalle, 9280 Sokak, No: 4, 07700 Elmalı, Antalya, Turkey.

E-mail: civanosman@gmail.com

Doi: $10.5606 /$ ehc. 2020.70955

Citation: Civan O, Şekerci R, Ercıkłı N, Özer Ș, Güvenç I, Keleș Çevik N, et al. Sesamoid bones of the hand: A multicenter study. Jt Dis Relat Surg 2020;31(1):68-72.

\section{ABSTRACT}

Objectives: This study aims to document a detailed investigation on the sesamoid bones (SBs) of Turkish subjects from different parts of Turkey in a multi-center study, in both hands, according to gender, frequency and divisions of the bones' coexistence and bilaterality by radiography.

Patients and methods: This retrospective and three-centered study was performed between June 2010 and April 2012. Sesamoid bones were examined by anteroposterior and oblique X-rays of 1,444 hands of 772 subjects (367 males, 405 females; mean age 42.7 years; range, 18 to 87 years). All X-rays were evaluated by at least two independent observers. In controversial circumstances, at least three observers together gave the final decision by consensus.

Results: Metacarpophalengeal (MCP) joint of the thumb (MCP 1) had sesamoid in all subjects $(100 \%)$ and it was seen bilaterally. The prevalence of the SB was $42.8 \%$ in the second MCP joint (MCP 2) in 772 subjects and $36.6 \%$ in 1,444 hands, $1.6 \%$ in the third MCP joint (MCP 3) for the subjects and $1.1 \%$ for the hands, $0.1 \%$ in the fourth MCP joint (MCP 4) for the subjects and $0.1 \%$ for the hands, and $72.5 \%$ in the fifth $\mathrm{MCP}$ joint (MCP 5) for the subjects and $62.5 \%$ for the hands. The prevalence of SB in the first interphalangeal joint (IP 1) was $21.8 \%$ and SB was detected in $18.6 \%$ of the hands. Sesamoid bones of the MCP 2, MCP 5, and IP 1 was recorded more frequently in females. Sesamoid bone of the same joints (MCP 2, MCP 5 and IP 1) was detected more frequently bilaterally than unilateral right side and more frequently unilaterally on right side than unilateral left side.

Conclusion: The distribution of SBs varies according to hand regions, gender, and side. Having knowledge of the locations and the rate of bilaterality of SBs may assist clinicians in both clinical and radiological diagnoses.

Keywords: Hand, interphalangeal sesamoids, metacarpophalangeal sesamoids, sesamoid bones, Turkish population.

and even the most common disorders of the SB (fracture, dislocations, arthritic, inflammatory and degenerative disorders) may be misdiagnosed. Trauma and degenerative disorders have been listed as the most common pathologic conditions of the SB. ${ }^{[7]}$ 
The incidence of SB in both hands and feet seems to vary according to racial groups. Most people have one SB in the metacarpophalangeal (MCP) joint of the small finger (MCP 5), one in the MCP joint of the index finger (MCP 2), one in the interphalangeal (IP) joint of the thumb and two in the MCP joint of the thumb (MCP 1). This shows that most people have five SBs in one hand ${ }^{[1,8]}$ and both the distribution and the prevalence of the SB of the hands vary in different populations and ethnic groups. ${ }^{[9-12]}$

In this study, we aimed to document a detailed investigation on the SBs of Turkish subjects from different parts of Turkey in a multi-center study, in both hands, according to gender, frequency and divisions of the bones' coexistence and bilaterality by radiography.

\section{PATIENTS AND METHODS}

This retrospective and three-centered (from different parts of Turkey) study was performed at Faculty of Medicine Department of Radiology of Çanakkale Onsekiz Mart University, Department of Radiology of Gülhane Military Medical Academy and Department of Orthopedics in Faculty of Medicine of Akdeniz University between June 2010 and April 2012. In this study, a total of 772 subjects (367 males, 405 females; mean age 42.7 years; range, 18 to 87 years) with anteroposterior (AP) and oblique bilateral hand X-rays were evaluated. X-rays of 970 hands of 485 subjects (237 males, 248 females; mean age 41.2 years; range, 18 to 87 years) were obtained from the first center; 202 hands of 101 subjects (70 males, 31 females; mean age 49.5 years; range, 18 to 76 years) were obtained from the second center; and 372 hands of 186 subjects (60 males, 126 females; mean age 43 years; range, 18 to 81 years) were obtained from the third center. Subjects aged under 18 years, those with congenital abnormalities of the hand, and those who were previously operated for severe hand injuries were excluded. All X-rays were evaluated by at least two independent observers. In controversial circumstances, at least three observers together gave the final decision by consensus. A written informed consent was obtained from each subject. The study was conducted in accordance with the principles of the Declaration of Helsinki.

\section{Statistical analysis}

The results were analyzed using the SPSS version 13.0 software (SPSS Inc., Chicago, NY, USA). Chi-square test was used to analyze categorical data and Bonferroni correction procedure was used in paired comparisons of more than two groups. $P$ value $<0.05$ was considered as statistically significant.

\section{RESULTS}

Two constant SBs were detected in the MCP 1 in all subjects $(100 \%)$. The prevalence of the SB in the MCP joints of the 772 subjects was $100 \%, 42.8 \%, 1.6 \%, 0.1 \%$, and $72.5 \%$, respectively (Table I).

Minimum one SB was found in the MCP 2 of 331 subjects (42.8\%) (Figure 1), in the third MCP (MCP 3) of 12 subjects (1.6\%) (Figure 2), in the fourth $\mathrm{MCP}$ (MCP 4) of one subjects (0.1\%) (Figure 3), and in the MCP 5 of 560 subjects (72.5\%) (Figures 1 and 4). Additionally, two SBs were detected in seven different hands $(0.4 \%)$ of seven different subjects $(0.9 \%)$ in the MCP 5 (Figures 1 and 3). One SB in the IP 1 joint was found in 169 subjects $(21.8 \%)$ and 270 hands (18.6\%) (Figure 4, Table I).

When we consider the gender distribution of the sesamoids; 187 subjects of MCP 2, seven subjects of MCP 3, 309 subjects of MCP 5, and 104 subjects of IP 1 were all females (total $n=405$ ) (Table I). The numbers

\begin{tabular}{|c|c|c|c|c|c|c|c|c|c|}
\hline \multirow[b]{3}{*}{ Sesamoid bones } & \multicolumn{8}{|c|}{$\begin{array}{l}\text { TABLE I } \\
\text { and distribution of sesamoid bones of hand region }\end{array}$} & \\
\hline & \multicolumn{2}{|c|}{$\begin{array}{l}\text { Prevalence } \\
\text { (Subject) }\end{array}$} & \multicolumn{2}{|c|}{$\begin{array}{l}\text { Prevalence } \\
\text { (Hand) }\end{array}$} & \multicolumn{2}{|c|}{ Gender } & \multicolumn{3}{|c|}{$\begin{array}{c}\text { Side } \\
\text { (Subject) }\end{array}$} \\
\hline & $n$ & $\%$ & $n$ & $\%$ & $\mathrm{~F}$ & M & Bilateral & Unilateral right & Unilateral left \\
\hline MCP 1 & 772 & 100 & 1,444 & 100 & 405 & 367 & 772 & - & - \\
\hline MCP 2 & 331 & 42.8 & 529 & 36.6 & 187 & 144 & 198 & 88 & 45 \\
\hline MCP 3 & 12 & 1.6 & 16 & 1.1 & 7 & 5 & 4 & 3 & 5 \\
\hline MCP 4 & 1 & 0.1 & 2 & 0.1 & - & 1 & 1 & - & - \\
\hline MCP 5 & 560 & 72.5 & 908 & 62.5 & 309 & 251 & 348 & 125 & 87 \\
\hline IP 1 & 169 & 21.8 & 270 & 18.6 & 104 & 65 & 101 & 45 & 23 \\
\hline
\end{tabular}




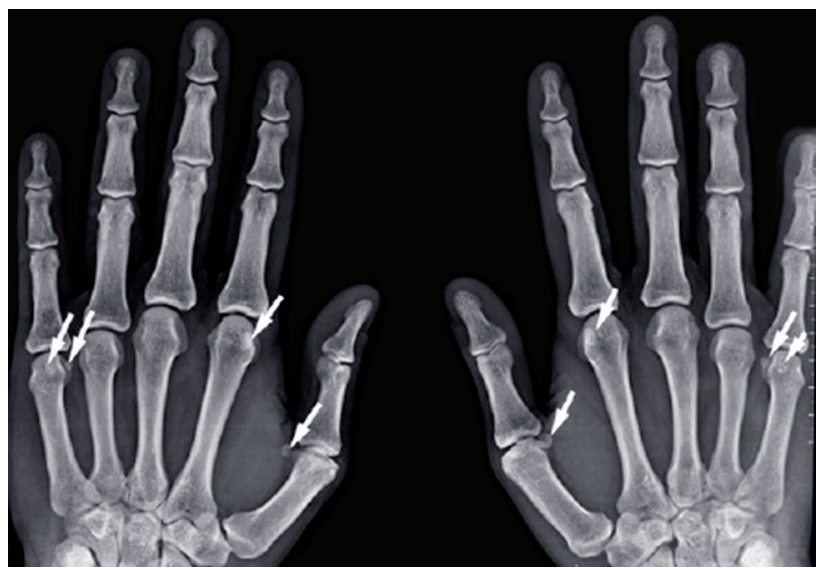

FIGURE 1. Plain anteroposterior radiographs of hand showing sesamoid bones. Sesamoid bones (arrows) are seen at metacarpophalangeal (MCP) 1, MCP 2, and MCP 5. Two sesamoid bones are present at MCP 5 .

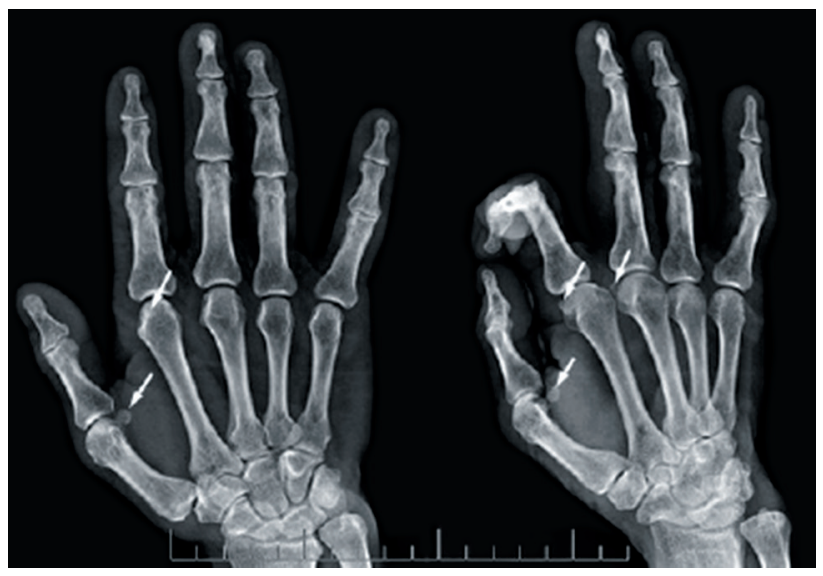

FIGURE 2. Plain anteroposterior radiographs of hand showing sesamoid bones. Sesamoid bones (arrows) are seen at metacarpophalangeal (MCP) 1, MCP 2, and MCP 3.

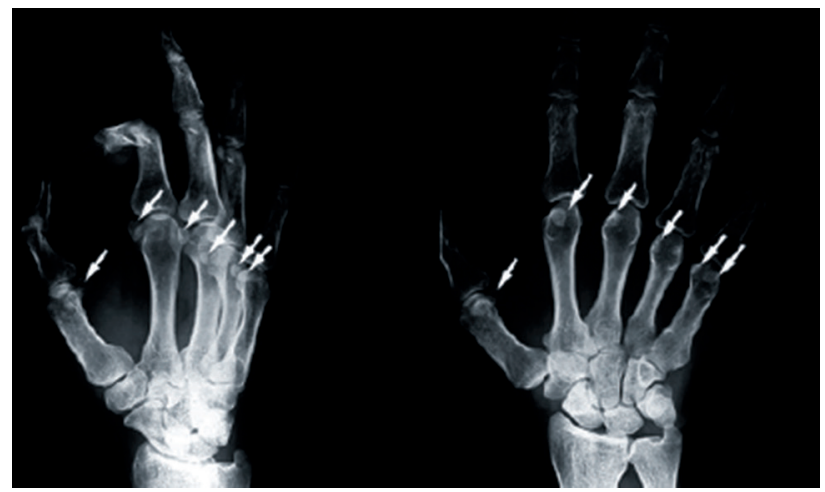

FIGURE 3. Plain anteroposterior radiographs of hand showing sesamoid bones. Sesamoid bones (arrows) are seen at metacarpophalangeal joints of all five digits. of male participants with sesamoids (total $\mathrm{n}=367$ ) were 144 , five, one, 251, and 65, respectively, in MCP 2, MCP 3, MCP 4, MCP 5, and IP 1 (Table I).

Sesamoid bones were categorized according to side (bilaterally, unilateral right and unilateral left) and detailed in Table I. Differences were statistically analyzed according to the side, gender, and presence or absence of SB. Sesamoid bone of the MCP 2, MCP 5, and IP 1 were recorded statistically significantly more frequently in females $(p=0.018$, $\mathrm{p}=0.014$, and $\mathrm{p}=0.003$, respectively). Sesamoid bones of the same joints (MCP 2, MCP 5, and IP 1) were detected statistically significantly more frequently bilaterally than the unilateral right side, and more frequently unilaterally on the right side than the unilateral left side ( $<<0.05$ for all) (Table II).

\section{DISCUSSION}

The number of SBs in the adult human skeleton can vary greatly for each individual. A majority of people have five SBs in one hand; two in the MCP 1, one in the IP 1, one in the MCP 2, and one in the MCP 5. ${ }^{[1,8]}$ Both the reason for pathogenesis and the precise number of these ossicles are not well known. Although SBs of the MCP 1 are considered as a normal skeleton part of adult human, sesamoids of other fingers are seen rarely. $[3,9,10]$

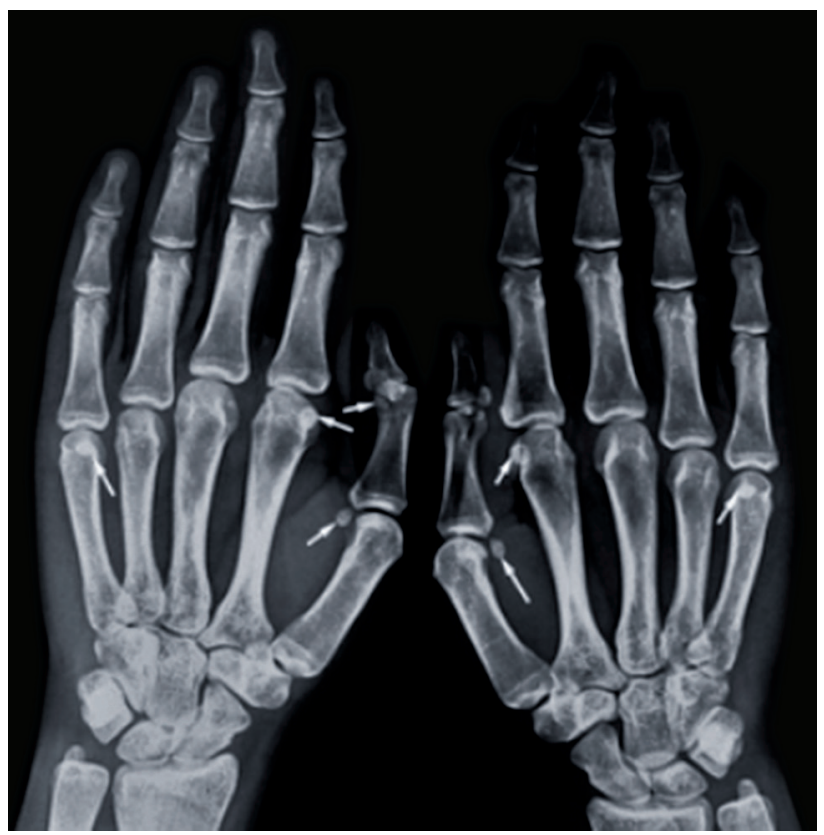

FIGURE 4. Plain anteroposterior radiographs of hand showing sesamoid bones. Sesamoids bones (arrows) are seen at metacarpophalangeal (MCP) 1, MCP 2 and, MCP 5. In thumb, one sesamoid bone is present at interphalangeal 1. 


\begin{tabular}{|c|c|c|c|c|c|}
\hline & & & $\begin{array}{r}\text { TABL } \\
\text { Statistical }\end{array}$ & & \\
\hline & & & Statistic & sis ( $p$ values) & \\
\hline Region & Gender & Side & Bilateral-unilateral right & Bilateral-unilateral left & Unilateral right-unilateral left \\
\hline MCP 1 & 0.171 & - & - & & \\
\hline MCP 2 & 0.018 & $<0.001$ & $<0.001$ & $<0.001$ & $<0.001$ \\
\hline MCP 3 & 0.564 & - & & & \\
\hline MCP 4 & - & - & & & \\
\hline MCP 5 & 0.014 & $<0.001$ & $<0.001$ & $<0.001$ & 0.027 \\
\hline IP 1 & 0.003 & $<0.001$ & $<0.001$ & $<0.001$ & 0.024 \\
\hline
\end{tabular}

MCP: Metacarpophalangeal; IP: Interphalangeal; Chi-square test was used to analyze categorical data while Bonferroni correction procedure was used in paired comparisons of more than two groups.

Kose et al. ${ }^{[13]}$ published the first sesamoid prevalence and a large series about the SB of Turkish hands. They reported $100 \%$ for MCP 1 sesamoids, $21.3 \%$ for IP 1, 36.6\% for MCP 2, 53.2\% for MCP 5, 1.3\% for MCP 3, and 0.9\% for MCP 4. ${ }^{[13]}$ Their results for MCP 1, IP 1, MCP 3, and MCP 4 were similar to our findings. However, results for the other areas were different. In that study, authors did not indicate the center where the research was conducted and the part of Turkey from where they obtained the radiographs. As Turkey is a large country with a heterogeneous structure, their results may be considered questionable. In the present study, 1,444 radiographs of 772 Turkish subjects' bilateral hands from different parts of Turkey were investigated. ${ }^{[14]}$

Sesamoid bones of the thumb are also useful in the diagnosis of systemic diseases and they are an indicator of pubertal growth. Enlargement of the thumb sesamoid is a feature of acromegaly. ${ }_{[}^{[8,15,16]}$ Descriptive anatomy of the thumb sesamoids has been examined in detail. They can appear as a bony formation in one hand and may be larger in the other hand and can appear like a fibrocartilaginous nucleus on the other side. ${ }^{[3]}$ The volar plate of the MCP involves both of the SBs. Bipartism of the thumb sesamoids was reported in rare cases; Pfitzner (cited by Fawcett, 1896) ${ }^{[17]}$ reported different bipartite SBs of MCP and IP joints. There are reports of three cases of isolated absence of the radial bone of MCP joint, and the absence of one or both sesamoids in the MCP joint of the thumb is exceptional. ${ }^{[3,17]}$ There are few reports of a possible association between sesamoid frequency and ossification period of sesamoids. ${ }^{[10,18]}$ With regard to SB in the digits of the hand in other studies $^{[9,10,19]}$ as in the present study, two SBs were seen on palmar side of the MCP joint of the thumb in all of the 1,444 hands of the 772 subjects. In our subjects, no bipartism of the thumb sesamoids was detected.

The sesamoid of the second finger, if present, is usually located on the radial side of the volar plate of the MCP joint. ${ }^{[3,12,17]}$ No intrinsic muscles are attached to the sesamoid of the second finger unlike the thumb. A sesamoid is always located in the radial side of the medius and on the ulnar side if present in the fourth finger. ${ }^{[12,17]}$ The reported prevalence at other locations ranges from 3.6 to $64 \%$, 0 to $5.3 \%, 0$ to $7.1 \%$, and 0 to $76.5 \%$ at MCP 2, MCP 3, MCP 4, and MCP 5, respectively. ${ }^{[3,9,10,12,18,19]}$ The $40.4 \%$ SB frequency of MCP 2 in Arab subjects is similar to the $35-64 \%$ reported in Caucasians..$^{[3,12]}$ Similarly, the $45.3 \%$ incidence of SB in the MCP 5 in the Arab population is comparable to that reported in Caucasians (44.6-76.5\%). ${ }^{[3]}$ Thus, the prevalence of SB in the index and little fingers in the Arab population seems to be similar to that in Caucasians, albeit close to the lower side of the frequency range. Although SBs have been described as being rare, or occurring infrequently ${ }^{[9,10]}$ in the MCP joints of the middle and ring fingers, Bizarro ${ }^{[3]}$ has reported a frequency of $7.1 \%$ at each of these sites in Caucasians, while the gender of the subjects were not mentioned. Dharap et $a{ }^{[10]}$ reported that the incidence of sesamoids at these two digits in the Arab population of Bahraini was found much lower: $2.3 \%$ in the third and 1.5\% in the fourth fingers, respectively. In the present study, the prevalence of SB in the MCP joints of the hands were $42.8 \%, 1.6 \%, 0.1 \%$, and $72.5 \%$ at MCP 2, MCP of the medius (MCP 3), MCP 4, and MCP 5, respectively. Moreover, we detected some statistically significant differences between males and females. Sesamoid bones of the MCP 2, MCP 5, and IP 1 were recorded statistically significantly more frequently in females $(\mathrm{p}=0.018, \mathrm{p}=0.014$, and $\mathrm{p}=0.003$, respectively). 
The sesamoid of the IP joint of the thumb is usually single and one single case of a double SB was reported by Bizarro. ${ }^{[3]}$ The incidence of SB in the IP 1 has been reported to be $100 \%$ in Africans ${ }^{[19]}$ and between $73 \%$ and $100 \%$ in Caucasians. ${ }^{[12,20]}$ According to all reports, this particular incidence differs greatly from that observed in the available literature, which may give rise to thought about racial variation.

Exceptionally, Seki et al. ${ }^{[21]}$ reported the following frequencies in the proximal IP joints of the fifth, fourth, and third fingers: $1 \%$ (two of 179), $0.5 \%$ (one of 183), and $0.4 \%$ (one of 244), respectively. Also, a sesamoid in the distal IP joint of a second finger was reported by Pfitzner (cited by Fawcett, 1896). ${ }^{[17]}$ In the present study, the prevalence of SB in the IP 1 joint was $21.8 \%$. In our subjects, sesamoids were not detected in any other IP joints.

This study has some limitations. Turkey is a big and multicultural country. All of the regions have different ethnic groups. We wanted to minimize the problems due to differences of the ethnics by selecting three different region of Turkey. New studies including all of seven regions of Turkey would be more interesting.

In conclusion, the present study represents a detailed report with particular emphasis on the prevalence of SB of the hand in Turkish subjects from different parts of Turkey. The distribution of SBs varies according to hand regions, gender, and side. Thus, the locations of SBs and the rate of bilaterality may assist clinicians in both clinical and radiological diagnoses.

\section{Declaration of conflicting interests}

The authors declared no conflicts of interest with respect to the authorship and/or publication of this article.

\section{Funding}

This work was supported by grants from the Akdeniz University Scientific Research Projects Management Unit, Antalya, Turkey.

\section{REFERENCES}

1. Yammine K. The prevalence of the sesamoid bones of the hand: a systematic review and meta-analysis. Clin Anat 2014;27:1291-303.

2. Abdel-Kader HM. The potential of digital dental radiography in recording the adductor sesamoid and the MP3 stages. Br J Orthod 1999;26:291-4.
3. Bizarro AH. On Sesamoid and Supernumerary Bones of the Limbs. J Anat 1921;55:256-68.

4. Seybold EA, Warhold LG. Impingement of the flexor pollicis longus tendon by an enlarged radial sesamoid causing trigger thumb: a case report. J Hand Surg Am 1996;21:619-20.

5. Yammine K. The relationship between digit independence and digital sesamoids in humans and a proposal of a new digital sesamoid evolutionary hypothesis. Anat Rec (Hoboken) 2018;301:1046-60.

6. Butt IS, Kim WY. Complex dorsal subluxation of the metacarpo-phalangeal joint of the thumb requiring open reduction: a case report. Acta Orthop Belg 2006;72:93-5.

7. Ozcanli H, Sekerci R, Keles N. Sesamoid disorders of the hand. J Hand Surg Am 2015;40:1231-2.

8. Wood VE. The sesamoid bones of the hand and their pathology. J Hand Surg Br 1984;9:261-4.

9. Amar E, Rozenblat Y, Chechik O. Sesamoid and accessory bones of the hand--an epidemiologic survey in a Mediterranean population. Clin Anat 2011;24:183-7.

10. Dharap AS, Al-Hashimi H, Kassab S, Abu-Hijleh MF. Incidence and ossification of sesamoid bones in the hands and feet: a radiographic study in an Arab population. Clin Anat 2007;20:416-23.

11. Goldberg I, Nathan H. Anatomy and pathology of the sesamoid bones. The hand compared to the foot. Int Orthop 1987;11:141-7.

12. Joseph J. The sesamoid bones of the hand and the time of fusion of the epiphyses of the thumb. J Anat 1951;85:230-41.

13. Kose O, Guler F, Turan A, Canbora K, Akalin S. Prevalence and Distribution of Sesamoid Bones of the Hand. A Radiographic Study in Turkish Subjects. Int. J. Morphol 2012:30:1094-9.

14. Atik OŞ. Is there something new and interesting in my article? Eklem Hastalik Cerrahisi 2019;30:69.

15. Steinbach HL, Feldman R, Goldberg MB. Acromegaly. Radiology 1959;72:535-49.

16. Kocakoc E, Kiris A, Ozgocmen S. Acromegalic arthropathy of the hand with sesamoid involvement: a case report. Hand Surg 2002;7:153-4.

17. Fawcett E. The Sesamoid Bones of the Hand: a Skiagraphic Confirmation of the Work done by Pfitzner. J Anat Physiol 1896;31:157-61.

18. Msamati BC, Igbigbi PS. Radiographic appearance of sesamoid bones in the hands and feet of Malawian subjects. Clin Anat 2001;14:248-53.

19. Oprea D, Baz R, Iliescu D, Bordei P. Morphological peculiarities of the sesamoid bones in the hand. Rom J Func Clin Macro Microsc 2012;11:28.

20. Gray DJ, Gardner E, O'Rahilly R. The prenatal development of the skeleton and joints of the human hand. Am J Anat 1957;101:169-223.

21. Seki Y, Hoshino Y, Kuroda H. Prevalence of sesamoid bones in the interphalangeal joint of the thumb and fingers: a radiographic study. Clin Anat 2013;26:823-6. 